\title{
Stable and active oxidation catalysis by cooperative lattice oxygen redox on $\mathrm{SmMn}_{2} \mathrm{O}_{5}$ mullite surface
}

Yongping Zheng ${ }^{1 \dagger}$, Sampreetha Thampy ${ }^{1}$, Nickolas Ashburn ${ }^{1}$, Sean Dillon ${ }^{1}$, Luhua Wang ${ }^{1}$, Yasser Jangjou ${ }^{2}$, Kui Tan ${ }^{1}$, Fantai Kong ${ }^{1}$, Yifan Nie ${ }^{1}$, Moon J. Kim¹, William S. Epling², Yves J. Chabal ${ }^{1}$, Julia W. P. Hsu' ${ }^{1}$ Kyeongjae Cho ${ }^{1 *}$

${ }^{1}$ Department of Materials Science and Engineering, University of Texas at Dallas, Richardson, TX 75080, USA

${ }^{2}$ Department of Chemical Engineering, University of Virginia, 102 Engineers' Way, Charlottesville, VA 229044741 

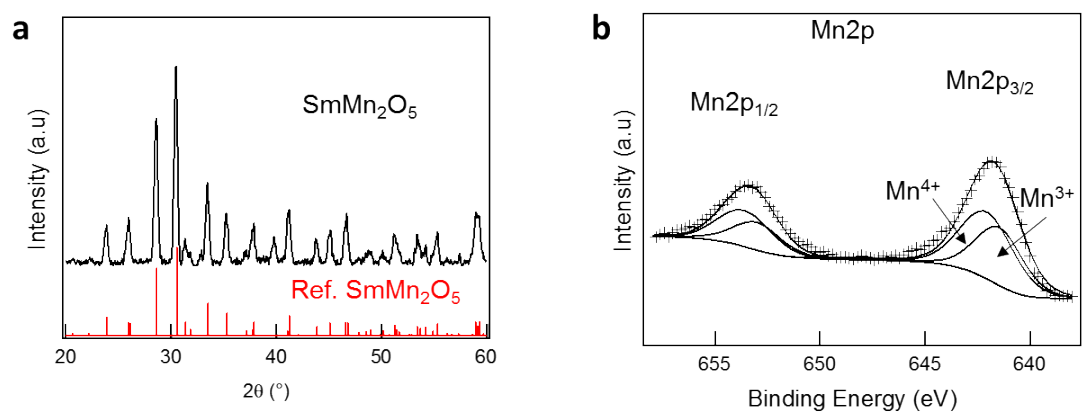

Supplementary Figure 1 | Characterization of mullite oxide powders. a, XRD pattern of $\mathrm{SmMn}_{2} \mathrm{O}_{5}$ oxides matches well with the reference diffraction data of $\mathrm{SmMn}_{2} \mathrm{O}_{5}$ (PDF\# 00-052-1096, red). b, XPS spectrum of the $\mathrm{Mn} 2 p$ core levels in $\mathrm{SmMn}_{2} \mathrm{O}_{5}$ can be deconvoluted into two peaks at $641.4 \mathrm{eV}$ and $642.0 \mathrm{eV}$, matching the binding energies of $\mathrm{Mn}^{3+}$ and $\mathrm{Mn}^{4+}$, respectively. 
Supplementary Table 1 | Overbinding errors of nitrogen related species calculated using DFT method with GGA-PBE function. The amount of molecular overbinding can be determined by comparing the calculated atomization energies with the experiment values from NIST thermodynamic database. We can see that the overbinding of $\mathrm{NO}_{x}$ species increase drastically with the valence increasing of nitrogen. The overbinding of $\mathrm{NO}, \mathrm{NO}_{2}$, surface nitrite $\left(\mathrm{NO}_{2}{ }^{-}\right)$and nitrate $\left(\mathrm{NO}_{3}{ }^{-}\right)$need to be corrected during the calculation of adsorption or desorption energies. The overbinding of $\mathrm{NO}_{2}{ }^{-}$and $\mathrm{NO}_{3}{ }^{-}$cannot simply adopt the values of $\mathrm{NO}_{2}$ and $\mathrm{NO}_{3}$ in gas phase, since the overbinding is valence dependent. We determined the overbinding values of $\mathrm{NO}_{2}{ }^{-}$and $\mathrm{NO}_{3}{ }^{-}$by calculating the overestimations of $\mathrm{DFT}+\mathrm{U}$ calculated $\mathrm{NO}$ desorption barriers (without overbinding corrections) compared to the NO-TPD derived values, and the overbinding of $\mathrm{NO}_{2}{ }^{-}$and $\mathrm{NO}_{3}{ }^{-}$equal to the overestimation of $\mathrm{NO}$ desorption barrier plus $\mathrm{NO}$ overbinding. We can see that the overbinding of surface $\mathrm{NO}_{2}^{-}$is in between the values of $\mathrm{NO}^{-}$and $\mathrm{HNO}_{2}$, and the overbinding of surface $\mathrm{NO}_{3}{ }^{-}$is in between the values of $\mathrm{NO}_{2}$ and $\mathrm{HNO}_{3}$, upholding the $\mathrm{N}$ valence dependent nature of $\mathrm{NO}_{x}$ species. The overbinding of surface $\mathrm{NO}_{2}{ }^{-}$and $\mathrm{NO}_{3}{ }^{-}$calibrated with NO-TPD give more reliable $\mathrm{NO}_{x}$ chemistry on the surface.

\begin{tabular}{|l|l|l|l|}
\hline \multirow{2}{*}{ Molecule } & \multicolumn{2}{|l|}{ Atomization energy (eV) } & \multirow{2}{*}{$\begin{array}{l}\text { Overbinding } \\
\end{array}$} \\
\cline { 2 - 3 } & Expt. (NIST) & GGA-PBE & \\
\hline $\mathrm{NO}$ & 6.51 & 7.15 & 0.64 \\
\hline $\mathrm{NO}_{2}$ & 9.62 & 11.20 & 1.58 \\
\hline $\mathrm{NO}_{3}$ & 11.75 & 14.15 & 2.4 \\
\hline $\mathrm{HNO}_{2}$ & 12.80 & 14.25 & 1.45 \\
\hline $\mathrm{HNO}_{3}$ & 16.08 & 17.96 & 1.88 \\
\hline Nitrite $\mathrm{NO}_{2}^{-}$ & $/$ & $/$ & 0.97 \\
\hline Nitrate $\mathrm{NO}_{3}^{-}$ & $/$ & $/$ & 1.64 \\
\hline
\end{tabular}


Supplementary Table 2 | DFT+U Calculated NO desorption barriers $\Delta \boldsymbol{E}_{b 1}, \mathrm{NO}_{2}$ desorption barriers $\Delta \boldsymbol{E}_{b 2}$, NO-TPD derived NO desorption barriers, and overbinding corrected $\mathrm{NO}$ and $\mathrm{NO}_{2}$ desorption barriers. The calculated NO desorption barriers ( $\Delta E_{b 1}$ ) shows huge overestimation when compared with TPD derived values, which is due to the overbinding of surface nitrite and nitrate calculated with GGA-PBE function. The GGA-PBE function is known to overestimate the bond strength of many covalent molecules like oxygen, as shown in Supplementary Table 2. The $\mathrm{NO}$ and $\mathrm{NO}_{2}$ desorption barriers with overbinding corrections show much better consistence with the experiment.

\begin{tabular}{|l|l|l|l|l|l|l|l|}
\hline $\begin{array}{l}\text { NO } \\
\text { coverage }\end{array}$ & \multicolumn{3}{|c|}{ DFT+U calculation } & \multicolumn{2}{l|}{$\begin{array}{l}\text { NO-TPD } \\
\text { experiment }\end{array}$} & \multicolumn{2}{l|}{$\begin{array}{l}\text { DFT+U+ } \\
\text { correction }\end{array}$} \\
\cline { 2 - 9 } & Configuration & $\begin{array}{l}\Delta E_{\mathrm{b} 1} \\
(\mathrm{eV})\end{array}$ & $\begin{array}{l}\Delta E_{\mathrm{b} 2} \\
(\mathrm{eV})\end{array}$ & $\begin{array}{l}\text { Peak } \\
\left({ }^{\circ} \mathrm{C}\right)\end{array}$ & $\begin{array}{l}\Delta E_{\mathrm{b} 1} \\
(\mathrm{eV})\end{array}$ & $\begin{array}{l}\Delta E_{\mathrm{b} 1} \\
(\mathrm{eV})\end{array}$ & $\begin{array}{l}\Delta E_{\mathrm{b} 2} \\
(\mathrm{eV})\end{array}$ \\
\hline$\theta=1$ & nitrite & 1.51 & 0.99 & 127 & 1.18 & 1.18 & 1.60 \\
\hline$\theta=0.5$ & nitrate & 2.40 & 1.72 & 221 & 1.43 & 1.40 & 1.64 \\
\hline$\theta=0.25$ & nitrate & 2.69 & 1.99 & 292 & 1.68 & 1.69 & 1.91 \\
\hline
\end{tabular}

